\title{
A urgência da leitura: Da guerra, de Clausewitz, no bloco de notas de Lênin
}

\section{The urgency of reading: Clausewitz's On War on Lenin's Notebook}

\section{DELMO OLIVEIRA ARGUELHES VÁGNER CAMILO ALVES}

\section{INTRODUÇÃO}

Quando da eclosão da assim chamada Crise de 1914 - período que vai do assassinato do arquiduque Franz Ferdinand, em 28 de junho, até o início da Grande Guerra de 1914-8-, em 4 de agosto Vladímir Lênin encontrava-se na cidade polonesa de Poronin, à época parte do Império Austro-Húngaro. Preso por doze dias em agosto de 1914, ele foi solto por intercessão do líder social-democrata local, Victor Adler, que enfatizou às autoridades locais a condição de inimigo do tsarismo do prisioneiro. No mês seguinte, Lênin e Nádia Krupskaia mudaram-se para a cidade de Berna, na neutra Suíça (Krausz 2017, 85). Em 1915, Lênin leu Da guerra, de Carl von Clausewitz (2010) com grande interesse, copiando e anotando trechos inteiros no bloco de notas, buscando refletir acerca das relações entre guerra e política.

Redigida por Clausewitz entre 1816 e 1830, Da guerra é um tratado essencial para o tema. Na nota final, acrescida pelo autor antes de partir para a campanha militar contra o levante polonês de 1830-1, apenas o capítulo 1 do livro I foi considerado concluído (2010, xcv). Clausewitz recusava-se a pensar a atividade bélica como conjunto de técnicas - geométricas e matemáticas, exatas —, ou mesmo como uma ciência, e sim como algo que remetia à arte, na medida que a criação e inspiração tem papel essencial na condução das operações militares. Neste símile, Clausewitz

Delmo Oliveira Arguelhes - Doutor em História das Ideias (UnB, 2008). Professor do Programa de Mestrado em Ciência Política da UniEURO. Pesquisador pós doutoral do INEST/UFF.

Vágner Camilo Alves - Doutor em Ciência Política pelo IUPERJ (2005) e professor associado do Instituto de Estudos Estratégicos da Universidade Federal Fluminense (INEST/UFF). 
pretendia negar caráter de certeza à guerra impresso por alguns autores dos oitocentos, como Henri Jomini e principalmente Heinrich von Bülow. Do mesmo modo, no livro I, Clausewitz compara os conceitos "guerra" e "jogo”, à medida que ambos são resultantes das interações de antagonistas, somadas à intervenção do acaso. No entanto, o general prussiano reiterou o caráter solene da atividade bélica, pois a guerra é um meio sério para atingir um fim sério $(2010,26)$. Nesse sentido, de acordo com o raciocínio de Clausewitz, a metáfora encontraria o limite final, apartando os dois conceitos. A guerra não seria um jogo, mas sim uma competição.

Entretanto, jogo e competição não são conceitos antitéticos. A competição está contida no jogo. Johan Huizinga (2008) expôs a tese de que o ato de jogar não é um elemento presente na cultura, mas sim é um elemento constituinte da cultura. O uso do genitivo não é fortuito. A precisão dessa construção frasal decorre do caráter de fundamento que a estrutura lúdica possui na formação da cultura (2008, vi). Uma das evidências para tal assertiva é a observação empírica que crianças e animais lutam "de brincadeira", ${ }^{1}$ sob regras livremente consentidas e experimentando um grande prazer nessa atividade (2008, 101); essas são características principais do jogo, segundo Huizinga. Ao contrário do que pressupunha Clausewitz, o fenômeno "jogo" também comporta a seriedade, apesar da seriedade excluir o mero jogo. Portanto, este conceito é mais abrangente do que aquele; assim como a competição. A palavra grega para competição solene, $\alpha \gamma \omega ́ v$, é raiz do adjetivo agonístico, qualidade essencial do combate. Parafraseando Clausewitz, apesar da competição ser um meio sério para objetivos sérios, outrossim está contida no conjunto maior, o jogo. As metáforas "guerra como jogo" e "jogo como guerra” são quase tão antigas quanto a origem da escrita.

Após a morte de Clausewitz, em 1831, a viúva deste dedicou-se à impressão de todos os escritos do marido. Em vida ele havia publicado tão-somente dois artigos, sob pseudônimo. Entre 1832 e 1837 foram lançados dez volumes, sob o título Hinterlassene Werke des Generals Carl von Clausewitz über Krieg und Kriegführung. O tratado Vom Krige (Da guerra) ocupa os três primeiros volumes da obra. A partir da vitória germânica na Guerra Franco Prussiana (1870-1), Da guerra alcançou fama para além das paredes do Estado Maior Geral do nascente império alemão.

Durante a estada na Suíça, Vladímir Lênin empreendeu grande esforço para compreender o mundo em violenta transformação, ao mesmo tempo que tentou - com grandes dificuldades - coordenar à distância as tarefas dos bolcheviques em São Petersburgo. Em 1915, Lênin leu Da guerra com grande interesse, tentando extrair dali algumas diretrizes para a luta revolucionária. As notas de Lênin sobre Clausewitz foram publicadas em 
Moscou, ainda nos anos 1920, sendo traduzidas para o francês e o inglês nas décadas seguintes. O objetivo principal deste artigo é justamente estudar os conceitos clausewitzianos - lidos, anotados e interpretados por Lênin durante o exílio suíço. Faremos, a seguir, uma breve exposição do pensamento de Clausewitz, no tocante à guerra, seguido da descrição e análise das notas de Lênin, indicando confluências e divergências entre ambos.

\section{A GUERRA É UM CAMALEÃO}

Mesmo inacabado e publicado postumamente pela viúva do autor, $D a$ guerra atesta um fôlego teórico gigantesco. Diversamente do descrito em outras obras até então, a guerra não seria uma atividade humana sobre massa inerte, unidirecional. É a colisão de duas forças vivas, donde fica estabelecido que o comportamento do outro é um dado fundamental (Clausewitz 2010, 11). O autor lança três definições acerca do fenômeno guerra: a) um duelo na mais vasta escala; b) um ato de violência com o intuito de submeter o adversário à própria vontade; e c) a continuação das relações políticas por outros meios $(2010,7 ; 27)$. A última - conhecida como o dictum - é a definição mais notória de Clausewitz, alvo de muitas críticas injustificadas. Injustificadas por não atingirem o cerne da definição.

O desarmamento do adversário, em Clausewitz, é o objetivo último da ação militar. Apenas através desse expediente pode-se obter a vitória no campo de combate, tornando possível a imposição da vontade sobre o inimigo. Invasão e ocupação de territórios e destruição das forças concorrentes não passam de meios para desarmar o oponente (Clausewitz 2010, 8).

Para que o adversário se submeta à nossa vontade, é preciso colocá-lo numa situação mais desfavorável do que o sacrifício que lhe exigimos. Todavia, a desvantagem não deve naturalmente ser transitória ou, pelo menos, aparentá-lo; caso contrário, o adversário esperaria um momento mais favorável e não cederia. Por conseguinte, qualquer mudança de situação que o arrasta no prosseguimento da atividade da guerra deve, pelo menos em teoria, conduzir a uma situação ainda mais desfavorável. A pior das situações para um beligerante é aquela em que este se encontra completamente desarmado (Clausewitz 2010, 10).

Portanto, mais do que a simples exibição de força, o objetivo da guerra é coagir o antagonista de que as exigências impostas são o mal menor em relação ao que está acontecendo e ao que pode ainda acontecer.

$\mathrm{O}$ dictum de Clausewitz, nomeado por Raymond Aron como formule (1986a, 12; 158ss), parte simplesmente da constatação que, dentre os mais variados caminhos para se atingir os objetivos nacionais, a guerra é um dos 
elementos presentes. O Homem de Estado pode usar relações diplomáticas, relações comerciais, investimento em educação, ciência e tecnologia ou a guerra, ${ }^{2}$ objetivando as metas previamente estabelecidas. Para se escolher esse ou aquele caminho, o Homem de Estado optaria pelos meios mais adequados aos objetivos. Ao contrário do entendimento rasteiro dos críticos, o general prussiano não afirmou que a política estatal deva ser violenta. Quase que diametralmente oposto, Clausewitz deixa bem claro no dictum a necessidade da preeminência dos objetivos políticos sobre a atividade guerreira. Mesmo na era nuclear, o dictum não perde a validade. Cálculos estratégicos jamais poderão suplantar, ou ignorar, os objetivos políticos, principalmente quando se depara com a possibilidade de destruição total. Inversamente a isso, o dictum é ainda mais necessário quando se coloca a questão nuclear nas considerações geopolíticas. Importante notar também que Clausewitz nunca afirmou que a natureza da guerra é racional; não existe qualquer base para se sustentar tal assertiva. Normativamente, ele demonstra que, em um Estado minimamente organizado, a decisão de declarar guerra deve ser ponderada com o máximo de atenção e reflexão considerando do primeiro ao último passo (Clausewitz 2010, 836) —, pois, conforme afirmação do mesmo autor, a guerra é o reino do perigo, além de ser - insistimos mais uma vez - um instrumento político.

O labirinto que se descortina a partir do recontro está expresso nas ações recíprocas ${ }^{3}$ de Clausewitz. Estas se estabelecem como ações intersubjetivas, tanto no plano tático quanto no estratégico. Por definição, tática é a arte de ordenar um exército para a batalha, de modo a enganar, ou surpreender, o adversário. Tal composição se dá pela disposição da força combatente em campo, como também pela ordem de entrada em batalha. A boa tática é aquela que o antagonista só percebe quando não há mais tempo hábil para executar qualquer contramedida. A estratégia, por sua vez, é a arte de combinar vários recontros de modo a vencer a guerra, ou seja, objetivando impor a própria vontade sobre o adversário, desarmando-o. Clausewitz sintetizou os dois fundamentos num artigo anônimo - para evitar represálias — no nono número da revista Neue Bellona (1805): "A tática constitui a teoria do emprego das forças armadas na batalha; a estratégia compõe a teoria do emprego da batalha para o objetivo da guerra" (apud Paret 2001, 263). O objetivo de uma guerra não é a conquista de território nem a destruição das forças oponentes. Ambos se constituem, no máximo, como meios de vencer o conflito.

A primeira ação recíproca de Clausewitz é o uso ilimitado da força, o que não significa o uso irracional ou desmedido.

Se a guerra é um ato de violência, também a sensibilidade necessariamente fará parte dela. Ainda que a guerra não provenha desta, 
incide, todavia, mais ou menos, sobre ela, e este mais ou menos não depende do grau de civilização, mas sim da importância e persistência dos interesses inimigos. [...]

A invenção da pólvora e os incessantes progressos no desenvolvimento das armas de fogo demonstram, por si, que, de fato, a tendência para destruir o inimigo, inerente ao conceito de guerra, não foi de modo nenhum entravada ou reprimida pelo progresso da civilização.

Repetimos, pois, a nossa afirmação: a guerra é um ato de violência e não há nenhum limite para a manifestação dessa violência. Cada um dos adversários executa a lei do outro, de onde resulta uma ação recíproca, que, enquanto conceito, deve ir aos extremos. Tal é a primeira ação recíproca e o primeiro extremo que se nos deparam (2010, 9-10).

A falta de limites para a manifestação da violência não implica necessariamente no cancelamento de qualquer vestígio de civilização. Mostra apenas que, se um antagonista traça limites, este fica em desvantagem. Basta que o adversário ultrapasse os mesmos limites para atingir a vitória. Entretanto, tal ato não pode ser feito sem planejamento ou inteligência. Mesmo que, num caso extremo, dois exércitos combatam-se sem uma animosidade prévia recíproca, esta, ao longo dos recontros, surgirá. O sentimento hostil anima as forças em luta, iniciando o movimento.

A segunda ação recíproca ocorre no recontro propriamente dito. Ações e reações contínuas de ambos os lados em combate subvertem o planejamento. Cada exército encontra-se preso ao adversário, numa teia ativa e reativa. "Eu não sou dono de mim próprio, visto ele [o adversário] me ditar as suas leis, assim como eu lhe dito as minhas" (Clausewitz 2010, 11). É impossível determinar com antecedência o resultado da batalha. A colisão de forças vivas, contida no recontro, desenha um quadro complexo de medidas e contramedidas. O planejamento de combate leva um comandante a imaginar e projetar a imaginação do outro, e vice-versa. As hostilidades conduzem a iniciativas, ações e reações; reavaliações, manutenções e modificações dos planos originais. Este planejamento é um ato intersubjetivo por excelência, onde o comandante coloca-se no lugar do outro, de modo a adivinhar-lhe as intenções; as projeções destas alimentarão o planejamento para o embate. As interações do recontro prendem os comandantes num labirinto mútuo. A reciprocidade dessa ação assenta-se no fato que o comandante adversário fará a mesma operação mental. Tal mudança de perspectivas deve necessariamente ser levada em consideração no exercício prospectivo, mesmo com o risco de projetar permutas ad infinitum. 
A terceira ação recíproca de Clausewitz recai na continuidade da avaliação constante do comportamento do outro, e nos próprios objetivos.

Se se quer vencer o adversário, deve-se proporcionar o esforço à sua força de resistência. Esta é o produto de dois fatores inseparáveis: $a$ extensão de meios de que dispõe o adversário e a firmeza de sua vontade. [...]

Supondo que a nossa estimativa sobre o poder de resistência do inimigo se ajusta mais ou menos à realidade, podemos então adequar proporcionalmente os nossos esforços a tal poder, intensificando-os de modo a assegurar o nosso predomínio [...]. [O $]$ adversário atua de maneira idêntica; de onde resulta uma nova competição que, em teoria pura, implica uma vez mais um impulso para os extremos $(2010,11)$.

Assim, o grau de indefinição de um recontro ou de uma campanha militar fica delineado no campo ideal. O movimento para superar o adversário sempre impele todos os lados ao extremo, unindo intenção hostil e planejamento. Essas três ações, portanto, constituem uma tríade. A primeira ação recíproca, o uso ilimitado da força, a despeito do grau de civilização dos povos em luta, corresponde à população e à violência originária da ação bélica. A segunda ação recíproca, o labirinto tático traçado pelos exércitos em luta, o qual enreda os próprios construtores, está ligada às forças de combate. Finalmente, a terceira ação recíproca, ligada à extensão dos meios disponíveis e à firmeza da força de vontade em atingir o objetivo, é a responsabilidade do governo.

Apesar de todos os exemplos, as ações recíprocas de Clausewitz desenvolvem-se no campo ideal. Na prática, a contenção dos atos bélicos advém, então, da esfera política, onde retomamos o dictum. A obstinação em perseguir um objetivo militar é proporcional à importância política do mesmo (Clausewitz 2010, 17-8). Em seguida, há o conhecimento imperfeito da situação (Clausewitz 2010, 22). Na melhor das hipóteses, o comandante das tropas conhece apenas a própria situação - se, por acaso, não tiver o hábito de punir mensageiros por más notícias. Assim, em determinados momentos, o combate pode ser substituído por tréguas tácitas momentâneas, objetivando a disponibilidade de informações suplementares ou ocasiões mais propícias. Haverá a tendência ao extremo, no entanto, se as autoridades políticas em conflito conferirem importância máxima ao objetivo.

As ações recíprocas já são suficientes, por si mesmas, para pontuar o grau de indefinição da atividade guerreira. No entanto, Clausewitz introduz um conceito que não pode deixar de ser considerado: o acaso, chamado por ele de friç̧ão. "Na guerra, tudo é muito simples, mas a coisa mais sim- 
ples é difícil. As dificuldades acumulam-se e levam a uma fricção da qual ninguém faz corretamente ideia se não viu a guerra" (Clausewitz 2010, 83). Se a vida cotidiana é marcada por imprevistos, em um combate, tais eventos se multiplicam exponencialmente. A fricção em Clausewitz funciona como a figura da Roda da Fortuna medieval. Enquanto na Antiguidade concebia-se a Fortuna como uma deusa, a qual sorria e favorecia a quem soubesse seduzi-la, os medievais imaginavam uma roda que girava aleatoriamente, distribuindo benesses ou desgraças sem qualquer padrão definido. Acreditamos que esta imagem é aquela a que devemos recorrer ao tratarmos da fricção em Clausewitz. A única certeza de que se dispõe é que acontecerá seguidas vezes durante a campanha militar, ajudando ou prejudicando as forças em combate. O remédio para tal espectro é o treinamento rigoroso dos soldados (Clausewitz 2010, 87), no sentido de desenvolvimento pleno das capacidades, como porta de entrada para o improviso no sentido positivo: saber adaptar-se diante das situações não esperadas.

O fenômeno bélico, em Clausewitz, se apoia num tripé: povo, exército e Estado.

A guerra, então, não é apenas um verdadeiro camaleão, que modifica um pouco a sua natureza em cada caso concreto, mas é também, como fenômeno de conjunto e relativamente às tendências que nela predominam, uma surpreendente trindade [grifo nosso] em que se encontra, antes de mais nada, a violência original do seu elemento, o ódio e a animosidade, que é preciso considerar como um cego impulso natural; depois, o jogo das probabilidades e do acaso, que fazem dela uma livre atividade da alma; e, finalmente, a sua natureza subordinada de instrumento da política por via da qual ela pertence à razão pura (2010,30).

Clausewitz pôde testemunhar, em seu breve tempo de vida, a característica mutante da guerra. Quando do seu alistamento, em 1792, o exército prussiano ainda estava submetido às táticas e às ordens de batalha da Europa seiscentista e setecentista, da Guerra dos Trinta Anos (1618-48) à Guerra dos Sete Anos (1756-63). Na Batalha de Iena (1806), entretanto, Napoleão destruiu o exército prussiano num único dia - destroçando-o enquanto os dedicados prussianos tentavam manobrar segundo os manuais militares tradicionais. Em 1815, durante a batalha de Waterloo, muitos princípios militares, antes tidos como basilares, já haviam caído por terra. As lições táticas aprendidas durante a Guerra Franco-Prussiana (1870-1) não se aplicavam à Grande Guerra de 1914-18. A dinâmica da guerra de trincheiras de 1914-18 não se repetiu na Segunda Guerra Mundial (193945). A forma de guerra total não foi mais praticada após 1945. A guerra é 
um camaleão. Mesmo assim, apesar de aparecer e parecer distinto a cada momento histórico — no sentido preciso de manifestação heideggeriana —, o fenômeno guerra permanece. ${ }^{4}$

Logo, o fenômeno se revela na totalidade; a mera manifestação e correlatos não passam ou de distorções do ente, ou tão somente uma superfície mutável ao longo do eixo diacrônico. Se a guerra é um camaleão, ela se manifesta dos mais diversos modos, porém mantém características próprias, que podem se revelar em si mesmas, fenomenologicamente. A trindade faz parte do fenômeno "guerra". A trindade clausewitziana atribui ao povo o ódio e a animosidade, ao exército as possibilidades e o acaso, e ao governo os objetivos políticos. Raymond Aron sintetiza tal trindade em "violência original, livre atividade da alma, entendimento político” (1986a, 235). As ações recíprocas de Clausewitz correspondem respectivamente à trindade. A guerra se revela em si mesma numa colisão sincrônica de trindades (Waldman 2009, 338).

Os três elementos da trindade, no entanto, não se constituem de modo estático, nem hierárquico.

A teoria que pretendesse pôr de parte alguma delas [das três tendências da trindade], ou que estabelecesse entre elas uma relação arbitrária, incorreria imediatamente numa tal contradição com a realidade que, só por essa razão, seria preciso considerá-la como nula.

O problema consiste, portanto, em manter a teoria no meio dessas três tendências, como que em suspensão entre três centros de atração (Clausewitz 2010, 30).

O conceito aqui apresentado guarda riqueza ímpar, e estas linhas introdutórias não podem, nem mesmo aspiram a esgotar o assunto. A trindade constitui um problema para os leitores de Clausewitz. Não é um problema por ser algum tipo de barreira intransponível ou completamente opaca a qualquer tentativa de interpretação. É justamente o oposto. Constitui um problema por ser um elemento aberto o bastante para permitir estudos e reinterpretações. Se um dos critérios essenciais para uma obra ser considerada clássica for a capacidade de sustentar diálogos, ao longo de incontáveis gerações, então Vom Kriege passou no teste com louvor.

\section{TRAJETÓRIAS DO TETRADKA}

O bloco de anotações de Lênin referente à leitura de Vom Kriege, Leninskaya Tetradka (Caderno de Lênin) está depositado, sob o número 18.674, nos Arquivos do Instituto Lênin, em Moscou. Publicado pela 
primeira vez no jornal Pravda, em 1923, foi editado por A. S. Bubnov, A. Toporkov, S. Ioffe, D. Rozenberg e V. Sidorenko. O prefácio foi redigido por A. S. Bubnov, e as notas explicativas escritas por A. Toporkov. Depois, a partir de 1930, essa edição foi republicada na antologia Leninskii sbornik (coletânea leninista), sob a edição geral de V. V. Adoratskii, V. M. Molotov e M. A. Savel'ev. A tradução para a língua francesa (Lênin 1945) manteve as notas explicativas. A tradução para a língua inglesa (Lênin 1977) manteve tanto as notas quanto o prefácio da edição original (Davis e Kohn 1977, 188; Kipp 1992, 81; Lênin 1945, 47; Aron 1986b, 59).

Lênin recebeu a primeira edição de Vom Kriege, em três volumes, das mãos de S. I. Gusev, militante bolchevique e antigo editor de uma enciclopédia militar. Na década anterior, Gusev esteve em contato com oficiais do generalato tsarista, encarregados da reforma do exército, após o desastre da Guerra Russo-Japonesa de 1905 (Kipp 1992, 68). Segundo Josef Stalin, Lênin teria lido Clausewitz tão somente pelo interesse na relação entre guerra e política, mas tal assertiva é tão rasa que se torna um truísmo (Davis e Kohn 1977, 189). Lênin buscava, dentre outras coisas, uma revisão radical do pensamento marxista acerca da guerra (Kipp 1992, 69). Sendo tal o pensamento holístico por princípio, o tema "guerra" só pode ser encaixado na narrativa após vários reparos. Como explicar o fracasso da II Internacional diante da Grande Guerra de 1914-18? Devemos sublinhar que a "solidariedade e internacionalismo" proletários foram suplantados pelos discursos nacionalistas locais, e a Trindade de Clausewitz explica de modo mais acurado tal mecanismo. Lênin passou a classificar as guerras pelo caráter político de cada força em luta. Foi assim que classificou a Grande Guerra como conflito imperialista. O objetivo ulterior da vanguarda revolucionária, portanto, seria converter tal conflito em guerra civil (Kipp 1992, 69). Ou seja, uma luta de classes continental, dos proletários contra a burguesia capitalista. Se a revolução, conforme projetava Marx, não nasceu de uma profunda crise econômica, poderia surgir de crise política, no meio de uma guerra generalizada.

No Tetradka, Lênin transcreveu trechos de 23 capítulos de sete livros de Vom Kriege. O único livro do qual ele não citou nenhum capítulo foi o IV, "O recontro", o qual trata da batalha em si, a partir dos desdobramentos operacionais. Os capítulos citados — precedidos dos livros em algarismos romanos - foram: O que é a guerra? (I, 1); O fim e os meios na guerra (I, 2); Acerca da teoria da guerra (II, 2); Arte da guerra ou ciência da guerra (II, 3); A propósito dos exemplos (II, 6); A virtude guerreira do exército (III, 5); A intrepidez (III, 6); A relação de força (V, 3); A relação das armas (V, 4); Caráter da defesa estratégica (VI, 5); Extensão dos meios de defesa (VI, 6); Métodos de resistência (VI, 8); Defesa em montanha (con- 
tinuação) (VI, 16); A defesa dos riachos e rios (VI, 18); Chave de país (VI, 23); Defesa de um teatro de guerra (continuação) (VI, 28); A defesa de um teatro de guerra quando não se procura a decisão (VI, 30); Natureza do ataque estratégico (VII, 2); Acerca dos objetivos do ataque estratégico (VII, 3); Guerra absoluta e guerra real (VIII, 2); Acerca da coesão interna da guerra e da grandeza do objetivo de guerra e dos esforços a fornecer (VIII, 3); Definição mais precisa do objetivo da guerra (continuação) (VIII, 5); Influência do objetivo político sobre o propósito militar e A guerra é um instrumento da política (VIII, 6) (Lênin 1945, 49-78).

Bubnov chama a atenção para algo crucial. O Tetradka não é um simples resumo do livro de Clausewitz, mas sim a indicação da leitura e interpretação que Lênin fez a partir da obra original, buscando caminhos e indicações para problemas práticos que se colocavam naquela época (1977, 193-4). Várias passagens foram acompanhadas pela sigla latina N. B. (nota bene), “perceba”, "preste atenção” (Davis e Kohn 1977, 188); uma convenção clássica para anotações nas margens das páginas. Os comentários começam no \$24 do capítulo 1, do primeiro livro: "A guerra é uma simples continuação da política por outros meios”. Não há excertos, nem observações sobre o caráter intersubjetivo da guerra, da colisão de forças vivas (segunda ação recíproca, $\$ 4$ do capítulo 1). Lênin começa com o dictum, incluindo a parte onde Clausewitz afirma ser impróprio pensar o meio (a guerra) independente do fim (a intenção política).

A primeira nota bene aparece após a citação do \$25 do capítulo 1, "Diversidade da natureza das guerras". A passagem de Clausewitz, copiada por Lênin, afirma o seguinte:

Quanto mais grandiosos e poderosos forem os motivos da guerra, quanto mais afetarem a própria existência da nação, quanto mais violenta for a tensão que precede a guerra, tanto mais a guerra será conforme à sua forma abstrata; e quanto mais ela procurar a destruição do inimigo, quanto mais a finalidade militar e os objetivos políticos coincidirem, tanto mais a guerra parecerá puramente militar e menos política. Mas, quanto mais fracos forem os motivos e a tensão, tanto mais a tendência natural do elemento de guerra, a tendência para a violência, coincidirá com as exigências políticas, e tanto mais a guerra se afastará da sua tendência natural, mais se aprofundará a diferença entre o desígnio político e a finalidade de uma guerra ideal, e mais a guerra parecerá tornar-se política [grifos nossos] (2010, 28).

A nota de Lênin, acompanhada de um N. B., na sequência imediata no Tetradka:

A aparência ainda não é realidade. Quanto mais uma guerra parecer "militar", mais profundamente será política; a guerra mais "po- 
lítica” parece ser menos profundamente política do que realmente é (Lênin 1945, 51; 1977, 196). ${ }^{5}$

Qualquer guerra é política, conforme conclusão de Clausewitz, referendada por Lênin. Porém, aqui vemos o intercâmbio entre fenômeno e aparência, no sentido heideggeriano dos termos, o que conduz ao fato de a guerra ser um camaleão (Clausewitz 2010, 30; Lênin 1945, 52; 1977, 196-7). A diferença de gradação entre a guerra real e a abstrata resulta do envolvimento da trindade no conflito. Lênin percebe que não há modulação em termos políticos, já que todas as guerras são políticas, mesmo que não apareçam como tal ou pareçam ser puramente militares. A variável aí é justamente a intensidade: a guerra absoluta, no extremo, leva a trindade igualmente em tal direção, enquanto a moderação da guerra real coloca limites nas ações recíprocas. A trindade, desenvolvimento imediato desse argumento clausewitziano, merece outra nota bene, desta vez para a citação direta. "O primeiro desses três aspectos interessa particularmente ao povo, o segundo, ao comandante e ao seu exército, e o terceiro importa sobretudo ao governo." (Clausewitz 2010, 30).

O comentário subsequente, no entanto, aparece com ênfases distintas, conforme a tradução:

Esta é uma observação muito apropriada a respeito da alma política, essência ou conteúdo da guerra, em oposição à sua aparência "popular". (Lênin 1977, 197).

Muito justo sobre a alma política, todo o conteúdo das guerras; e a exterioridade, do "povo"! (Lênin 1945, 52).

A versão de Davis e Kohn, mais sucinta e, aparentemente, mais árida, denota um comentário sóbrio, sem maiores desdobramentos. A versão francesa, de Friedl, por outro lado, quer indicar uma ênfase acentuada, ou, no sentido quase oposto, talvez possível ironia, sugerida pelo sinal de exclamação. O contexto do Tetradka não nos permite concluir pela última opção. Ao contrário, a exclamação poderia indicar surpresa ou uma reafirmação do conteúdo. Raymond Aron, entretanto, prefere acreditar na existência de tal ironia:

A seu ver [Lênin], a política constitui o essencial, o sentido profundo da guerra. Também, quando recopia em seu caderno a definição trinitária (\$28), uma anotação na margem mostra o esquerdismo da interpretação (grifo nosso). Com efeito, escreve: [“] muito justo para a alma política, a essência, o conteúdo da guerra e o elemento popular, exterior. ["] (grifado no original). Clausewitz não pensava em nada semelhante, mas Lênin conseguia, por meio desta via, reduzir a uma 
simples aparência (ou a um fenômeno superficial) a paixão dos povos, a adesão das massas à guerra. (Aron 1986b, 60)

Aron considerou uma leitura "esquerdista" - sem explicitar o motivo de tal classificação - a vontade e o cálculo políticos da trindade como elementos interiores, a alma da guerra, e a hostilidade popular como a manifestação exterior, e, mais ainda, interior e exterior em oposição um ao outro. No entanto, Clausewitz deixa bem claro que não há: a) uma relação arbitrária entre as três tendências, e b) não é possível considerar qualquer uma delas isoladamente, sem o conjunto, mesmo que as três possam variar, cada uma, de grandeza. A teoria da guerra fica em suspensão entre os elementos da trindade (2010, 30). Lênin tão somente concluiu que a animosidade popular se manifesta exteriormente, enquanto o cálculo táticoestratégico e a avaliação política manifestam-se internamente, como um assunto de Estado. Talvez o reparo que se possa fazer à avaliação de Lênin é que os exércitos em marcha não deixam de ser uma manifestação exterior - e por demais concreta — da trindade guerreira. Contudo, ainda não conseguimos enxergar aqui o viés "esquerdista” da interpretação.

O Tetradka segue com o segundo capítulo do livro 1, "Os fins e os meios na guerra”. Neste capítulo, Clausewitz afirma que, se o objetivo da guerra é desarmar o inimigo, tal expediente é atingido através de três pontos do antagonista (os quais correspondem diretamente à Trindade): forças militares, território e a vontade do inimigo (2010, $31 \mathrm{ss}$ ). As forças militares adversárias têm que ser destruídas e o território, conquistado, Lênin resumiu, como o caminho para quebrar a vontade do inimigo e, assim, o forçar a assinar a paz $(1945,53 ; 1977,197)$, o que justamente Clausewitz concluiu no seguimento do capítulo. Do outro lado, o país invadido também pode mobilizar povo e território contra o invasor. Mesmo uma derrota honrada pode, no futuro, abrir caminho para a insurreição (Lênin 1945, 57-8; 1977, 200). Um simples habitante não influencia mais a zona de batalha do que uma gota num oceano, mas o povo, como um todo, pode pender a balança, mesmo se não houver dinâmicas de insurreição (Lênin 1945, 59; 1977, 201).

A Chave de País, conceito usual dos defensores da dita ciência militar, seria a região "sem o domínio da qual jamais se cometerá a imprudência de penetrar no país” (Clausewitz 2010, 633). Clausewitz critica tal concepção em Vom Kriege, argumentando que, para além dos cálculos matemáticos e geométricos, tal chave é muito mais uma figura retórica (2010, 637). Lênin acompanha tal argumentação, citando outra passagem que "a melhor chave de país reside no exército inimigo” (Lênin 1945, 61; 1977, 202). Afinal, guerra e jogo são atividades análogas, e o labirinto estratégico construído pelas forças em choque demonstra tal assertiva (Lênin 1945, 64; 1977, 204). 
Nesta seção, o que atraiu muito da nossa atenção foi uma ausência. Não há referência direta ao capítulo 26 do Livro VI, "O armamento do povo". Tal capítulo consiste, em síntese, em um país invadido - portanto, lutando defensivamente - por uma potência estrangeira mobilizar a população civil para atuar como partisans, os quais combaterão atrás das linhas inimigas (2010,669ss). O exército de partisans opera nos princípios da assim chamada petit guerre ou guerrilla - objeto de várias preleções e aulas proferidas por Clausewitz na Escola Geral de Guerra de Berlim, a Allgemeine Kriegesschule, em 1810-11 - usando a tática do "bater e correr", ou seja, ataques relâmpagos ou atos de sabotagem contra as tropas invasoras e dispersão imediata, confundindo-se com os demais civis — estes encarregados de fornecer proteção e abrigo aos soldados irregulares. É flexível o bastante para dificultar a repressão, porém tem a capacidade de desferir golpes consideráveis no adversário, se espalhando como um incêndio no campo (Clausewitz 2010, 670). Tal expediente, no entanto, deve ser utilizado em conjunto com um exército permanente, mantendo a pressão e tomando a iniciativa diante do antagonista.

“O armamento do povo", desde o início, mostrou-se um capítulo problemático. Clausewitz o iniciou na defensiva, afirmando que, se os detratores enxergavam esse expediente como algo perigoso e revolucionário, ele evitaria descrever os aspectos políticos e trataria tão somente dos operacionais. Por mais de um século, tal capítulo foi suprimido das edições organizadas pelo Estado Maior prussiano - e posteriormente o alemão - e dos demais congêneres europeus (Aron 1986b, 91-2). A ausência de tal capítulo no Tetradka, portanto, é gritante. A presença desse capítulo em Vom Kriege não é fortuita. Clausewitz, além das palestras proferidas acerca da resistência espanhola, ainda tinha em mente o édito prussiano sobre o Landsturm, a milícia popular, de 21 de abril de 1813. Era convocação - surpreendentemente assinada pelo próprio rei da Prússia, algo inédito até então — à população para resistir à invasão estrangeira, leia-se, no caso, francesa.

Todo cidadão - assim como consta no édito real prussiano de abril de 1813 - está obrigado a oferecer resistência ao inimigo invasor por meio de armas de toda a espécie. São expressamente recomendados (no \$43) machados, forcados, foices e espingardas de caça. Todo cidadão prussiano está obrigado a não obedecer a nenhuma ordem do inimigo, e sim a prejudicá-lo por todos os meios que puder empregar. Mesmo se o inimigo quiser restabelecer a ordem pública, a ninguém lhe é permitido obedecer, pois com isso ficam facilitadas ao inimigo suas operações militares. Consta expressamente que "desordens de corjas desenfreadas" são menos nocivas do que uma situação em que o inimigo possa dispor livremente de todas as suas 
tropas. São asseguradas represálias e ações de terror para a proteção do partisan e com elas se ameaça o inimigo. Em suma: tem-se aqui uma Magna Carta do partisan. Em três trechos - na introdução e nos $\$ \S 8$ e 52 - faz-se referência direta à Espanha e a sua guerrilha como "modelo e exemplo". O combate é justificado como um combate em legítima defesa, "a qual consagra todos os meios" ( $\$ 7)$, inclusive o desencadeamento da total desordem (Schmitt 2009, 192).

Este texto impressionante, no entanto, teve vida efêmera e foi revogado em menos de três meses, em 17 de julho de 1813. As motivações para tanto são bem claras, e explicam, inclusive, as reservas de Clausewitz ao iniciar o capítulo. Um decreto dessa espécie poderia permitir uma leitura radical, fornecendo a justificativa para que massas revoltadas com os governantes pudessem considerar estes como "invasores inimigos", "traidores da nação”, ou até "maus cidadãos”. Assim o diploma legal poderia ser interpretado como uma autorização para a sedição.

O que não ficou claro é o motivo que levou Lênin a não comentar diretamente tal parte, justamente a mais revolucionária, em termos políticos, do tratado. Nos capítulos anteriores, dentro do Livro VI (a defesa), há menções tanto à resistência da população, quanto à possibilidade de sublevação geral no território ocupado, com comentários de Lênin. Isso faz a ausência dos excertos e comentários diretos sobre o "Armamento do povo" ainda mais eloquente. Carl Schmitt cita um artigo de Lênin publicado na revista russa $O$ proletário, em 1906, intitulado Partisanenkampf (o combate partisan), colocando o tipo como personagem importante nas guerras civis nacionais e internacionais. Este seria um "eficiente instrumento da liderança central do partido comunista” (Schmitt 2009, 198). A guerra partisan é basilar para fazer a revolução comunista em todos os países do mundo. “[O] que serve a este objetivo é bom e justo" (Schmitt 2009, 199). O artigo também sugere dois tipos de partisan: os combatentes pela paz e heróis gloriosos, conduzidos pelo partido; e a corja de canalhas e inimigos da humanidade que se recusam a se submeter ao controle do partido (Schmitt 2009, 199). É curioso notar, para além das conclusões óbvias na superfície de tal assertiva, que os combatentes pela paz se encaixam na trindade, atuando como braço armado do Partido.

Na parte dedicada ao terceiro tomo de Vom Kriege, Lênin se debruça no capítulo 2 do livro VIII, “Guerra absoluta e guerra real”. Nos excertos copiados, consta que, até o século XVIII, a guerra era um problema exclusivo dos governantes, e o povo participava de maneira lateral. Boa parte das guerras surgiam como indignação mútua, e ambos os lados se preparavam buscando proteção, ocasionalmente desferindo um golpe pretensamente 
decisivo. Lênin comenta, ao longo de tal assertiva: "todas as guerras eram tais que ambos os lados apenas se defendiam." Então, "sob Bonaparte a guerra atinge sua característica absoluta" (1945, 66; 1977, 206). Lênin chama a atenção, além do período transcrito, com vários nota bene e anotações laterais, para o argumento clausewitziano da inclusão da população inteira na guerra. A guerra absoluta depende, também, das massas (1945, $68 ; 1977,207)$. Uma teoria acerca da guerra, que se pretenda séria, tem que levar em conta todas as peculiaridades, que se desdobram ao longo do eixo sincrônico, e não, como muitos autores fazem, descartar como anomalia tudo aquilo que não se encaixasse no próprio arrazoado teórico.

Sendo a guerra "apenas uma parte das relações políticas e, por conseguinte, de modo algum independente” (Clausewitz 2010, 870), essa é causada apenas pelas relações políticas entre os povos (Lênin 1945, 71; 1977, 209). A guerra, apesar de possuidora de uma gramática própria, não tem uma lógica distinta; é tão somente a parte de um todo. Este conjunto é a esfera política (Lênin 1945, 72; 1977, 210). Assim, mesmo num cenário de guerra absoluta, a subordinação do ponto de vista político ao militar seria um contrassenso, tão somente porque a "política cria a guerra" (Clausewitz 2010, 873; Lênin 1945, 74; 1977, 212), e a guerra é um instrumento da política e não o inverso. A condução da guerra pode até marcar a substituição da pena pela espada, mas não suspende as próprias regras (Lênin $1945,77 ; 1977,214)$.

Há uma interpretação majoritária acerca do conceito guerra absoluta, em Clausewtiz, onde tal formato faria a política desaparecer completamente da cena. Essa se baseia essencialmente no $\$ 23$ do capítulo 1, Livro 1:

a guerra é um ato político. Todavia, se fosse um ato completamente autônomo, uma manifestação de violência absoluta, tal como se poderia concluir do seu puro conceito, a guerra tomaria o lugar da política, a partir do instante em que fosse provocada por esta, eliminá-la-ia e seguiria suas próprias leis como uma coisa inteiramente independente (2010, 26. Grifos nossos).

Mesmo no texto original, em alemão, o condicional se aparece; não foi um erro ou deslize da tradução: "Er [Der Krieg] ist also ein politischer Akt. Wäre er nun ein vollkommener, ungestörter, eine absolute Äußerung der Gewalt $(. . .)^{\prime 6}$ (Clausewitz 2012, pos. 715). Portanto, a partir desse excerto podemos propor outra interpretação, de que a guerra absoluta seria a negação da esfera política se e somente se a guerra fosse concebida como fenômeno autônomo. Tal interpretação ainda encontra guarida no Livro VIII, capítulo 2: "poder-se-ia duvidar da realidade da nossa noção, da sua essência absoluta, se não tivéssemos visto nos nossos dias a guerra real em sua per- 
feição absoluta.” (Clausewitz 2010, 830-1). Tal assertiva se faz necessária aqui, pois as observações de Lênin seguem nesta mesma direção (Lênin 1945, 51, 65ss; 1977, 196, 205ss). Lênin interpretou a guerra absoluta de Clausewitz não como a negação da esfera política, onde esta desapareceria sob a extensão das operações militares. Guerra absoluta, para Lênin, significa a destruição do inimigo, como condição de vida para o vitorioso.

Não podemos perder de vista que o Lênin de 1915, leitor e comentador de Clausewitz, não é o mesmo Lênin de 1918, dirigente máximo do partido, ocupado em manter a revolução bolchevique viva, assegurando o poder no solo russo. Quando a Revolução de Outubro ultrapassou o tempo de existência da Comuna de Paris (1871), surpreendendo tanto os bolcheviques quanto seus numerosos adversários, Lênin comemorou efusivamente. Ele mesmo não acreditava, à época, que iriam tão longe (Reis 2017, 46). Lênin, em 1915, pensava numa guerra absoluta de classes, de onde emergiria a completa vitória dos oprimidos sobre os opressores.

Lênin encerra o Tetradka com uma citação, a qual não pertence ao Vom Kriege, e sim ao manuscrito Um resumo de instrução militar dado pelo autor à Sua Majestade Real, o Príncipe Herdeiro, nos anos 1810, 1811 e 1812.

Em termos políticos, a guerra defensiva é uma guerra onde se luta pela própria independência. Estrategicamente, guerra defensiva significa uma campanha limitada a combater o inimigo num teatro de guerra o qual foi preparado previamente para tal propósito. Se neste teatro de guerra se luta defensivamente ou ofensivamente, não faz nenhuma diferença $(1945,77-8 ; 1977,214)$.

A guerra revolucionária é explicitamente defensiva, de acordo com Lênin. Além de significar a libertação das massas oprimidas, esta se justifica pela causa em si. A promessa de liberdade é capaz de arregimentar o povo, pronto para ser conduzido pelo Partido, o qual providenciaria a liderança política e organizaria as forças militares. A luta de classes ganharia organização, além do direcionamento correto, dentro da concepção clausewitziana. Para os planos leninistas, a guerra revolucionária seria a aplicação da guerra absoluta na realidade factual.

\section{CODA}

Lênin, mais do que simplesmente anotar os escritos de Clausewitz, fez uma leitura profunda e reflexiva. A teoria da guerra marxista - i.e. deduzida a partir dos escritos de Marx e Engels - a situava como um fenômeno da superestrutura. A guerra sempre estaria presente, enquanto houvesse a possibilidade de apropriação dos meios de produção. A leitura 
de Vom Kriege, em 1915, representou inflexão marcante no pensamento de Lênin. Mais profundo do que a assertiva stalinista, Lênin explorou ao máximo as conexões entre guerra e política expostas no tratado, além das relações dos entes da trindade. Ao invés de um etéreo salto de um modo de produção para outro, a luta revolucionária, em Lênin, ganhou um modelo mais palpável. Assim a Grande Guerra apresentava a oportunidade de se transformar numa guerra civil mundial, do proletariado contra a classe dominante. Mesmo com a mudança de objetivos imediatos, da revolução permanente à defesa do socialismo num só país, a concepção de Lênin no pensamento militar soviético teve peso considerável.

Devemos apontar também que a concepção de estado em Clausewitz e Lênin diferiam em essência, porém não no lugar que ocupavam na divisão trinitária. Clausewitz não entra em detalhes acerca do estado, mas o pressupõe como uma entidade acima da sociedade, o qual trabalha pelo melhor interesse dela. Lênin, por sua vez, via o Estado - na melhor tradição marxista - como um agente dos interesses das classes dominantes. No Tetradka, podemos deduzir o papel intercambiável do Partido Bolchevique na trindade. Na fase de guerra civil, ocuparia o papel do estado. Posteriormente, de 1918 em diante, teria o controle do Estado russo e, a partir de 1922, Soviético.

Neste ponto, a guerra revolucionária se aproximaria muito do ideal defensivo delineado por Clausewitz — e reafirmado por Lênin —, e poderia ser ligada ao famoso capítulo 26 do Livro VI, "O armamento do povo". Lênin a considerou de pouca importância para ser comentada? Redundante, por conta do artigo de 1906? Foi suprimida posteriormente ao arquivamento, e antes da publicação no Pravda em 1923? Se a palavra proibida numa charada, geralmente, é o objeto da charada, e, mesmo admitindo que adentramos o terreno da mera especulação com todos esses questionamentos, o armamento do povo não seria então esse objeto? Perguntas destinadas a não ter resposta aqui, mas que guardam grande potencial de reflexão.

\section{REFERÊNCIAS}

Aron, Raymond. 1986a. Pensar a guerra, Clausewitz — 1. A era europeia. Tradução de Elisabeth Maria Speller Trajano. Brasília: Edunb.

1986b. Pensar a guerra, Clausewitz — 2. A era planetária. Tradução de Elisabeth Maria Speller Trajano. Brasília: Edunb.

Bubnov, A. S. 1977. "Preface” In Donald E. Davis, and Walter S. G. Kohn. "Lenin's Notebook on Clausewitz". In Soviet Armed Forces Review Annual Jones, edited by David R. 1. Gulf Breeze: Academic International Press, 188-229. [Translation 
of Vypuski $i$ zamechaniia na knigu Klauzerwitsa "O voine $i$ vedenii voin" (Editions and annotations on Clausewitz's book On War and the Conduct of Wars), edited by A. S. Bubnov et al. In Leninskii sbornik, edited by V. V. Adoratskii, V. M. Molotov, and M. A. Savel'ev. 2. ed. Moscow-Leningrad, 1931, XII, 387-452.] https://www. clausewitz.com/bibl/DavisKohn-LeninsNotebookOnClausewitz.pdf.

Clausewitz, Carl von. 2008. On war. Translated by Michael Howard. Princeton: Princeton University Press. Kindle.

2010. Da guerra. Tradução de Maria Teresa Ramos. 3. ed. São Paulo: Martins Fontes.

2012. Vom Kriege. Altenmünster: Jazzybee Verlag. Kindle.

Davis, Donald E., and Walter S. G. Kohn. 1977. “Lenin's Notebook on Clausewitz”. In Soviet Armed Forces Review Annual 1, edited by David R. Jones, 188-229. Gulf Breeze: Academic International Press. https://www.clausewitz.com/bibl/ DavisKohn-LeninsNotebookOnClausewitz.pdf.

Heidegger, Martin. 2006. Ser e tempo. Tradução de Márcia Sá Cavalcante Schuback. Petrópolis; Bragança Paulista: Vozes; São Francisco.

Howard, Michael. 2008. "The influence of Clausewitz". In On war, Carl von Clausewitz. 27-44. Translated by Michael Howard. Princeton: Princeton University Press. Kindle.

Huizinga, Johan. 2008. Homo ludens: o jogo como elemento da cultura. Tradução de João Paulo Monteiro. 5. ed. São Paulo: Perspectiva.

Keegan, John. 1995. Uma história da guerra. Tradução de Pedro Maia Soares. São Paulo: Companhia das Letras.

Kipp, Jacob. 1992. "Lenin and Clausewitz: the militarization of Marxism, 19151921". In Soviet military doctrine from Lenin to Gorbachev, 1915-1991, edited by Willard C. Frank, Jr., and Philip S. Gillette. Westport: Greenwood Press, 63-83.

Krausz, Tamás. 2017. Reconstruindo Lênin: uma biografia intelectual. Tradução de Baltazar Pereira. São Paulo: Boitempo.

Lênin, Vladímir Ilitch. 1945. "Leninskaya tetradka - Cahier de Lénine $\mathrm{N}^{\circ} 18.674$ des Archives de l'Institute Lénine à Moscou". In Les fondements théoriques de la guerre et de la paix en U.R.S.S - suivi du cahier de Lénine sur Clausewitz, edited by Berthold C. Friedl. 47-78. Paris: Medicis. 
1977. "Notebook on excerpts and remarks on Carl von Clausewitz, On war and conduct of war". In Davis, Donald E. and Walter S. G. Kohn. "Lenin's Notebook on Clausewitz". In Jones, David R. (editor). Soviet Armed Forces Review Annual 1. Gulf Breeze: Academic International Press, pp. 188-229. [Translation of Vypuski $i$ zamechaniia na knigu Klauzerwitsa "O voine $i$ vedenii voin" (Editions and annotations on Clausewitz's book On War and the Conduct of Wars), edited by A. S. Bubnov et al. In Leninskii sbornik, edited by V. V. Adoratskii, V. M. Molotov, and M. A. Savel'ev. 2. ed. Moscow-Leningrad, 1931, XII, 387-452.] https://www. clausewitz.com/bibl/DavisKohn-LeninsNotebookOnClausewitz.pdf.

Paret, Peter. 2001. "Clausewitz". In Construtores da estratégia moderna: de Maquiavel a Era Nuclear - tomo 1, edited by Peter Paret. 257-92. Tradução de Joubert de Oliveira Brízida. Rio de Janeiro: Bibliex.

2008. "The genesis of On War". In On war, Carl von Clausewtiz. 3-26. Translated by Michael Howard. Princeton: Princeton University Press, Kindle.

Renouvin, Pierre, and Jean-Baptiste Duroselle. 1967. Introdução à história das relações internacionais. Tradução de Hélio de Souza. São Paulo: DIFEL.

Reis, Daniel Aarão. 2017. A revolução que mudou o mundo: Rússia, 1917. São Paulo: Companhia das Letras.

Schmitt, Carl. 2009. O conceito do político / Teoria do partisan. Tradução de Geraldo de Carvalho. Belo Horizonte: Del Rey.

Waldman, Thomas. 2009. War, Clausewitz, and the Trinity. Warwick: University of Warwick (PhD Thesis, Department of Politics and International Studies). 


\section{NOTAS}

1. Enquanto a língua portuguesa distingue os verbos "jogar" e "brincar", não há tal separação nas línguas holandesa, alemã ou inglesa. Nas duas primeiras, tais atividades estão contidas no verbo Spiel; este tem o mesmo campo semântico do verbo inglês to play: jogar, brincar, tocar um instrumento, atuar.

2. Pierre Renouvin e Jean-Baptiste Duroselle (1967, 333ss) afirmam que o Homem de Estado - presidente, rei, imperador, primeiro ministro, condestável, generalíssimo, dentre outras designações — é o responsável, em última instância, pela determinação dos objetivos nacionais de um país, sofrendo influência das forças profundas, ao mesmo tempo em que tenta moldá-las. As forças profundas seriam, grosso modo, as conjunturas políticas/econômicas/sociais do país, região e até de toda a comunidade internacional; o posicionamento geográfico do país e as percepções geopolíticas. Deste modo, o Homem de Estado estabelece os fins a serem alcançados e calcula os meios disponíveis para tanto. Tal movimento é antes normativo do que vinculativo.

3. Wechselwirkung (2012, cap. 1) no original. Esse termo significa na língua portuguesa ação recíproca, o qual é exatamente a tradução presente na edição brasileira de Vom Kriege (2010, 10ss). A tradução inglesa, de Michael Howard (2008, 77ss), verteu o termo como case of interaction. "Caso de interação” não chega perto da significação de movimento contida na palavra "recíproca". A característica que mais salta aos olhos da tradução de Howard é a aridez do texto, em confronto com a riqueza do original. Isso foi bem notado na tese de doutoramento de Thomas Waldman (2009, 382-4). Davis e Kohn, ao traduzirem o Tetradka de Lênin - que incluía alguns excertos no original de Vom Kriege, entremeados com anotações e sublinhados - para a língua inglesa, estavam bem conscientes dos limites da tradução. "Carl von Clausewitz’s monumental study was written in the early part of the nineteenth century. His sentences were long, his style was complex, and his phrases were involved; yet his words were carefully chosen. Rendering this prose into meaningful modern English is not without problems.” (1977, 188).

4. Heidegger distinguia fenômeno de manifestação, em benefício do rigor do método fenomenológico descrito na introdução da obra Ser e tempo (2006). "Fenômeno, mostrar-se em si mesmo, significa um modo privilegiado de encontro. Manifestação, ao contrário, indica no próprio ente uma emissão referencial, de tal maneira que o referente (o que anuncia) só pode satisfazer a sua possível função de referência se for um "fenômeno”, ou seja, caso se mostre em si mesmo. Manifestação e aparência se fundam, de maneira diferente, no fenômeno. Essa multiplicida- 
de confusa dos "fenômenos" que se apresenta nas palavras fenômeno, aparência, aparecer, parecer, manifestação, mera manifestação, só pode deixar de nos confundir quando se tiver compreendido, desde o princípio, o conceito de fenômeno: o que se mostra em si mesmo" (Heidegger 2006, 70).

5. Para traduzir com menos imprecisões os comentários de Lênin, feitos originariamente em russo, cotejamos simultaneamente as duas versões disponíveis, em francês (1945) e inglês (1977).

6. "Portanto, a guerra é um ato político. Se fosse uma expressão completa, imperturbável, absoluta de violência $[\ldots]$ ”.. 


\section{A URGÊNCIA DA LEITURA: DA GUERRA, DE CLAUSEWITZ, NO BLOCO DE NOTAS DE LÊNIN}

\section{RESUMO}

Durante o exílio na Suíça, Vladímir Lênin não tinha muitas opções de ação além da leitura sistemática de obras clássicas e de missivas dos camaradas que ainda estavam no Império Russo. Em 1915, de posse da primeira edição de Vom Kriege, em três volumes, Lênin empreendeu leitura profunda da obra clássica de Carl von Clausewitz, comentando diversos excertos. O objetivo deste artigo é analisar a interpretação feita pelo líder bolchevique, a partir das anotações legadas à posteridade.

Palavras-chave: Estudos Estratégicos; História das Ideias; Carl von Clausewitz; Vladímir Lênin.

\section{ABSTRACT}

During his exile in Switzerland, Vladímir Lenin did not have many options for action besides the systematic reading of classic works and letters from his comrades who were still within the Russian Empire. In 1915, in possession of the first edition of Vom Kriege, in three volumes, Lenin undertook a thorough reading of the classic work by Carl von Clausewitz, commenting on several excerpts. The objective of this paper is to analyze the interpretation made by the Bolshevik leader, from the notes bequeathed to posterity.

Keywords: Strategic Studies; History of Ideas; Carl von Clausewitz; Vladímir Lênin. 